\title{
Varietal differences in deoxynivalenol and its glucoside (modified mycotoxin) content in forage corn inoculated with Fusarium graminearum
}

\author{
Shohei Mitsuhashi ${ }^{1}$, Hiroyuki Nakagawa ${ }^{2,3}$, Yosuke Matsuo ${ }^{2}$, \\ Tomohiro Kikawada ${ }^{4}$, Hiroyuki Tamaki ${ }^{1}$, Hisashi Sato ${ }^{4}$ \\ 1 NARO Institute of Livestock and Grassland Science, 768 Senbonmatsu, Nasushiobara, Tochigi 329-2793, Japan \\ ${ }^{2}$ NARO Food Research Institute, 2-1-12 Kannondai, Tsukuba, Ibaraki 305-8642, Japan \\ ${ }^{3}$ NARO Advanced Analysis Center, 2-1-12 Kannondai, Tsukuba, Ibaraki 305-8642, Japan \\ ${ }^{4}$ NARO Hokkaido Agricultural Research Center, 1 Hitsujigaoka, Toyohira, Sapporo, Hokkaido 062-8555, Japan
}

\author{
Keywords \\ Deoxynivalenol; \\ Deoxynivalenol-3-glucoside; \\ Fusarium graminearum; \\ Modified mycotoxin; Zea mays L.

\section{Correspondence \\ Shohei Mitsuhashi, NARO Institute of Livestock and Grassland Science, 768 Senbonmatsu, Nasushiobara, Tochigi 329-2793, Japan \\ E-mail: shouheim@affrc.go.jp}

(Received January 11, 2019, revised January 29, 2019, accepted February 4, 2019)

\begin{abstract}
To identify varietal differences in deoxynivalenol (DON) and deoxynivalenol-3-glucoside (D3G) content in forage corn in Japan, field experiments involving fungal inoculations were conducted. High levels of DON content were observed in both the silk insertion and kernel injection experimental plots, probably because of favorable environmental conditions including that of temperature and rainfall. A variety 'Kimimaru', resistant to Fusarium ear rot and fumonisin contamination, is a key contributor to DON contamination resistance. D3G concentration was lower than that of DON in all experimental plots. Some varieties had low DON content and high D3G/ DON ratio in the silk insertion. Since the D3G/DON ratio is an indicator of DON detoxification activity, further evaluation of these varieties is required. The coefficients of determination for DON and D3G content were significant in both plots $\left(R^{2}=0.90\right.$ and 0.54 , respectively). Although the toxicity of D3G is lower than that of DON, most of the varieties examined in this study accumulated non-negligible D3G. Since the data in this study was obtained from a single-year trial, further studies are required for future breeding and stable forage supply.
\end{abstract}

\section{Introduction}

The fungal pathogen Fusarium graminearum is the most common agent of Gibberella ear rot of corn (Zea mays L.). The outbreak of this disease reduces crop yield and results in mycotoxin contamination in fermented silage or harvested cereals. Among the Fusarium mycotoxins, a trichothecene deoxynivalenol (DON) is the most critical in Japan because of its high toxicity, causing immune depression, digestive disorders, or deterioration of feeding preference for livestocks ${ }^{1), 2)}$, and its frequent outbreak in Japan, including in Hokkaido, the northernmost island where dairy farming is an important industry ${ }^{3)}$.

DON-producing Fusarium graminearum fungus has the ability to weaken plant tissues in order to infect easily ${ }^{4), 5)}$. Plant tissues also have their own anti-toxicity systems to prevent such infections, mostly by employing a UDP-glucosyltransferase that detoxifies DON by glucosylating the $-\mathrm{OH}$ at the $\mathrm{C}-3$ position, which significantly contributes to the toxicity of $\mathrm{DON}^{6), 7)}$. The compound produced in this reaction is DON-3-glucoside (D3G), and detoxified mycotoxins such as D3G are known as "modified" mycotoxins ${ }^{8}$.

The objective of this study was to identify varietal differences in DON and D3G content in forage corn in a field experiment conducted in Hokkaido, Japan.

\section{Materials and Methods}

\section{Plant materials}

Ten elite maize $F_{1}$ varieties bred at the HARC (NARO Hokkaido Agricultural Research Center), two commercial varieties, and three old varieties were used in this study (see Results section). Most of the varieties had not been evaluated for their resistance to DON 
and D3G contamination, except 'Ohzora' and 'Tiberius' (adopted as control varieties).

\section{Chemicals and standards}

A standard solution of D3G $(50 \mathrm{mg} / \mathrm{L}$ in acetonitrile) was purchased from Fujifilm-Wako Chemicals (Osaka, Japan). Acetonitrile (LC-MS grade) was obtained from Fisher Scientific (Waltham, MA), and distilled water (LC-MS grade) from Kanto Chemical (Tokyo, Japan). DON was purchased from Fujifilm-Wako. Ammonium acetate (chemically pure grade) was from Kanto Chemical, and acetic acid ( $>99.9 \%$ of chemically pure grade, not glacial) was from Fujifilm-Wako. All other reagents were of analytical grade.

\section{Fungal strain for inoculation}

A DON-producing $F$. graminearum strain (isolated from Hokkaido in 2009 and deposited in the Genebank, Genetic Resources Center, NARO, Japan as MAFF 242587) was used in this study. The strain was initially multiplied in Petri dishes filled with PDA (Potato Dextrose Agar) medium, and incubated at $25^{\circ} \mathrm{C}$ for 10 days. Several culture fragments punched using a cork borer were transferred to a flask filled with $135 \mathrm{~mL}$ of modified Bilai's medium ${ }^{9}$. The solution was placed on a shaker for 7 days ( $135 \mathrm{rpm}$ ) and maintained at $25^{\circ} \mathrm{C}$. Filtered spores were adjusted to $1 \times 10^{6} / \mathrm{mL}$ concentration as a spore suspension in distilled water and stored in a freezer. For inoculating corn plants, the spore suspension was melted and an aliquot $(20 \mu \mathrm{L})$ was re-cultured with $200 \mathrm{~mL}$ modified Bilai's medium for 7 days, and adjusted to appropriate spore counts as described later.

\section{Field trials}

The field experiments were conducted at NARO HARC, Sapporo, Japan (altitude of 67 meters above sea level, coordinate $43^{\circ} \mathrm{N}, 141.4^{\circ} \mathrm{W}$, with an average annual precipitation of $1106 \mathrm{~mm}$ ), during the summer season (May to September) in 2015. In the early spring, $30 \mathrm{t} / \mathrm{ha}$ of manure, $1.5 \mathrm{t} / \mathrm{ha}$ of calcium carbonate, 500 $\mathrm{kg} / \mathrm{ha}$ of fused phosphate, $1 \mathrm{t} / \mathrm{ha}$ of fertilizer (containing $14 \%$ each of $\mathrm{N}_{1} \mathrm{P}_{2} \mathrm{O}_{5}$ and $\mathrm{K}_{2} \mathrm{O}$ ) and $50 \mathrm{~kg} / \mathrm{ha}$ of insecticide (diazinon granule) were applied prior to seeding. Some herbicides ( $5 \mathrm{~L} / \mathrm{ha}$ of dimethenamid- $P$ and linuron emulsion, $2 \mathrm{~L} / \mathrm{ha}$ of atrazine and S-metolachlor wettable powder) were also applied after seeding. The experimental design used was a split plot design with three replications. The main plots were inoculated using the following methods: silk insertion or kernel injection ${ }^{10), 11)}$ and the subplots were the tested varieties. All the varieties were grown in single row plots ( 3.3 $\mathrm{m}$ in length, $0.75 \mathrm{~m}$ apart) each comprising 18 plants. The inoculation was done at 10 days after the silking stage in each line. The techniques used were: (i) insertion of $0.1 \mathrm{ml}$ of the $1 \times 10^{7} / \mathrm{mL}$ spore suspension in the silk channel of the primary ear (silk insertion), and (ii) injection of $0.5 \mathrm{ml}$ of the $5 \times 10^{5} / \mathrm{mL}$ spore suspension through the husk leaves to the side of the primary ear (kernel injection) (Fig. 1). When each of the varieties reached the yellow-ripe stage (about 40 days after silking), harvested ears were collected and stored in a convection drying system maintained at $60^{\circ} \mathrm{C}$ for a week. Ten dried ears per plot were ground to $4 \mathrm{~mm}$ size and used for the extraction and purification of mycotoxins.
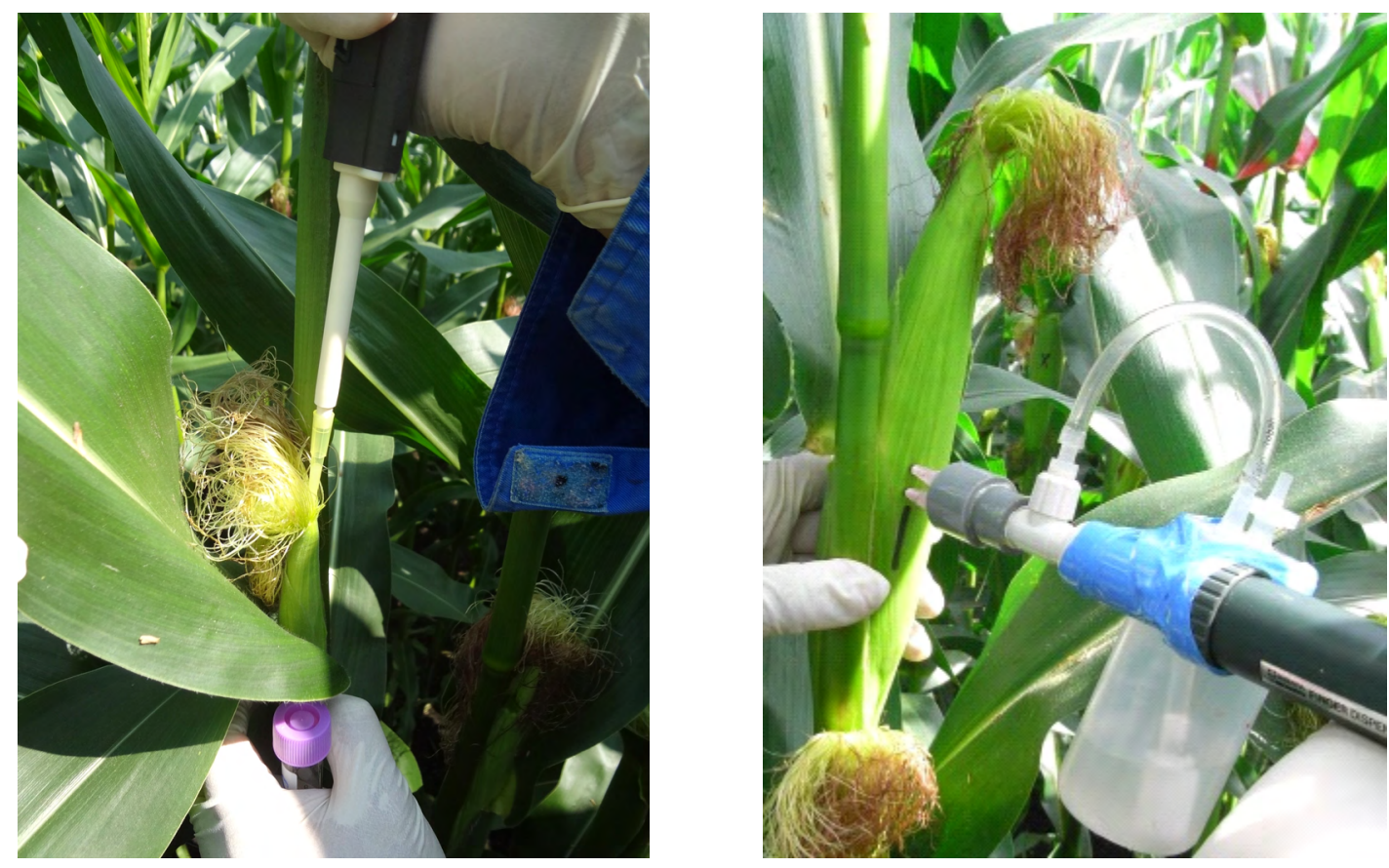

Fig. 1 Inoculation methods used in this study. (left: silk insertion, right: kernel injection) 


\section{Preparation of stock and working solutions for chemical analysis}

Mycotoxin stock solutions were calibrated the NARO Food Research Institute as described below. DON obtained in the crystalline form was accurately weighed and individually dissolved in acetonitrile. The solvent volume was adjusted to yield concentrations of $100-200 \mathrm{mg} / \mathrm{L}$. D3G solution in acetonitrile was used as the stock at a concentration of $50 \mathrm{mg} / \mathrm{L}$. These stock solutions were stored in amber glass containers at $4{ }^{\circ} \mathrm{C}$ to prevent photo-degradation of the mycotoxins and evaporation of the solvent. As an internal standard solution, verrucarol (VEL) was dissolved in acetonitrile at a concentration of $100-200 \mathrm{mg} / \mathrm{L}$, and also stored in amber glass containers at $-20^{\circ} \mathrm{C}$. The VEL stock solution was appropriately diluted with acetonitrile and used for spiking and preparation of working solution. For working solution, each stock solution (DON, D3G) was taken, dried under a nitrogen gas stream, and dissolved again by diluting in acetonitrile/water/acetic acid (5/94/1, v/v/v) as described previously ${ }^{12)}$.

\section{Extraction and purification of mycotoxins}

Extraction, purification, and determination of mycotoxins were performed at the NARO Food Research Institute in 2017 as described in previous work ${ }^{12)}$. The method was further confirmed as valid for D3G in wheat and barley flours ${ }^{13}$. Each ground sample (corn powder, $10 \mathrm{~g}$ ) was taken in glassware and fortified with $0.5 \mathrm{~mL}$ of internal standard solution (VEL $2 \mathrm{mg} / \mathrm{L}$ in acetonitrile) to adjust its final concentration as $0.1 \mathrm{mg} / \mathrm{kg}$. After storing in the refrigerator for more than $12 \mathrm{~h}$, the fortified samples were left at room temperature for approximately $30 \mathrm{~min}$. Thereafter, $40 \mathrm{~mL}$ of acetonitrile/water $(80 / 20, \mathrm{v} / \mathrm{v})$ and $0.4 \mathrm{~mL}$ of acetic acid (> 99.9 $\%)$ were added, and the mixture was homogenized for $5 \mathrm{~min}$ or vigorously shaken for $30 \mathrm{~min}$. The extract was centrifuged at 2,000 $\times \mathrm{g}$ for $10 \mathrm{~min}$, and an aliquot of the supernatant $(15 \mathrm{~mL})$ was loaded onto a solid-phase Presep C18 extraction (SPE) column (ODS) $(2 \mathrm{~g} / 15 \mathrm{~mL})$ (Fujifilm-Wako, Part No. 296-34091). The resulting eluate was subsequently loaded in a multifunctional Bond Elut Mycotoxin column (Agilent Technologies, Santa Clara, CA). After discarding the initial $3 \mathrm{~mL}$ of the solvent flowing through the column, $1.6 \mathrm{~mL}$ of aliquot from the subsequent eluate was transferred to a new tube, and dried under a nitrogen gas stream at $40{ }^{\circ} \mathrm{C}$. The residue was dissolved again in $0.4 \mathrm{~mL}$ of acetonitrile/water/acetic acid (5/94/1, v/v/v) and filtered using a DISMIC-13 HP hydrophilic PTFE disposable syringe filter unit (pore size, $0.20 \mu \mathrm{m}$ ) (Toyo Roshi Kaisha, Ltd., Tokyo, Japan), and the resultant filtrate was subjected to LC-MS/MS analysis.

\section{Analysis of mycotoxins}

Detection and quantification of mycotoxins were performed using a 4000 QTRAP LC-MS/MS system (Sciex, Foster City, CA) equipped with a 1290 Series HPLC system (Agilent Technologies). Chromatographic separation was performed at $40^{\circ} \mathrm{C}$ on a ZORBAX Eclipse XDB-C18 RRHD Solvent Savor column $(150 \mathrm{~mm} \times 2.1$ $\mathrm{mm}$ i.d., $1.9 \mu \mathrm{m}$ particle size) (Agilent Technologies). Eluate consisted of water/acetic acid (99.9: 0.1, v/v) containing $0.5 \mathrm{mmol} / \mathrm{L}$ ammonium acetate (eluate $\mathrm{A}$ ), and acetonitrile/acetic acid (99.9: 0.1, v/v) (eluate B), with stepwise gradient for $13.8 \mathrm{~min}$ (0-1 min: hold $12 \%$ B; 1-6.5 min: from $12 \%$ to $68 \%$ B; $6.5-9$ min: from $68 \%$ to $85 \%$ B; $9-10$ min: hold $85 \%$ B; $10-10.1$ min: from 85 $\%$ to $12 \%$; $10.1-13.8$ min: hold $12 \%$ B to equilibrate). Three $\mu \mathrm{L}$ of each sample was injected and ionization was performed with an electrospray ionization (ESI) probe in negative polarity. Data was acquired in the multiple reaction monitoring (MRM) mode of the LC$\mathrm{MS} / \mathrm{MS}$, and the ions were selectively monitored for detection of the respective mycotoxins, as shown in Table 1.

\section{Determination of DON and D3G content}

The amounts of DON and D3G were determined based on the average of measurements on samples prepared in duplicate from each maize extract, using three sets of [precursor-product] ions to ensure accuracy. The lower limits of quantification (LOQ) for both DON and D3G were $10 \mu \mathrm{g} / \mathrm{kg}$, respectively. The D3G/ DON ratio was calculated from the absolute values of DON and D3G using the following equation:

$$
\begin{aligned}
& \text { D3G/DON ratio }=(\mathrm{D} 3 \mathrm{G}(\mathrm{mg} / \mathrm{kg}) / 517.1) / \\
& (\mathrm{DON}(\mathrm{mg} / \mathrm{kg}) / 355.1) \times 100
\end{aligned}
$$

\section{Statistical Analysis}

To compare the levels of DON and D3G content among the varieties in dried ears, Tukey's HSD test was used with R 3.43 ${ }^{14)}$, and "multcomp" package ${ }^{15}$. We also used R 3.43 to determine the correlation between DON and D3G.

Table 1 LC-MS/MS parameters of each analyte studied

\begin{tabular}{ccc}
\hline Analyte & Precursor ion & Product ion \\
\hline DON & 355.1 & 294.8 \\
$\left(\mathrm{C}_{15} \mathrm{H}_{20} \mathrm{O}_{6}\right)$ & {$\left[\mathrm{C}_{15} \mathrm{H}_{20} \mathrm{O}_{6}+\mathrm{CH}_{3} \mathrm{COO}\right]^{-}$} & 264.8 \\
& & 58.9 \\
$\mathrm{D} 3 \mathrm{G}$ & 517.1 & 456.9 \\
$\left(\mathrm{C}_{21} \mathrm{H}_{30} \mathrm{O}_{11}\right)$ & {$\left[\mathrm{C}_{21} \mathrm{H}_{30} \mathrm{O}_{11}+\mathrm{CH}_{3} \mathrm{COO}\right]^{-}$} & 426.9 \\
& & 58.9 \\
VEL & 325.2 & 58.8 \\
$\left(\mathrm{C}_{15} \mathrm{H}_{22} \mathrm{O}_{4}\right)$ & {$\left[\mathrm{C}_{15} \mathrm{H}_{22} \mathrm{O}_{4}+\mathrm{CH}_{3} \mathrm{COO}\right]^{-}$} & \\
\hline
\end{tabular}




\section{Results and Discussion}

Typical LC-MS/MS chromatograms are shown in Fig. 2. Both DON and D3G were simultaneously detected in the negative polarity environment. Using a semi-micro RRHD column and the two-step gradient of mobile phase, separation was achieved within $14 \mathrm{~min}$ (DON: $2.8 \mathrm{~min}$, D3G: $2.3 \mathrm{~min}, \mathrm{VEL}: 4.6 \mathrm{~min}$ ).

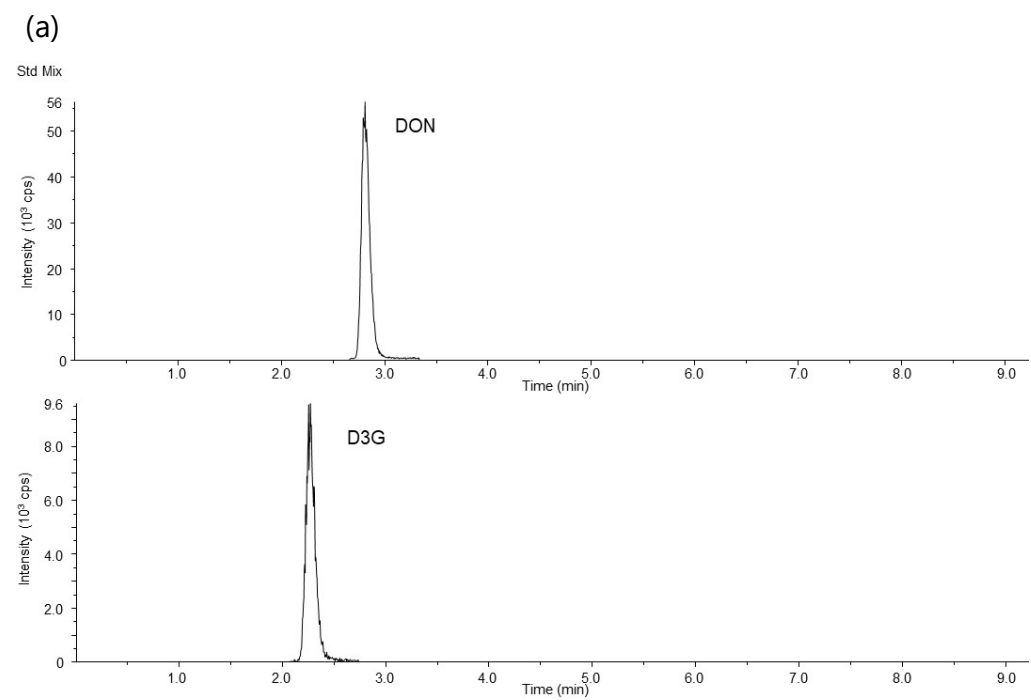

(b)
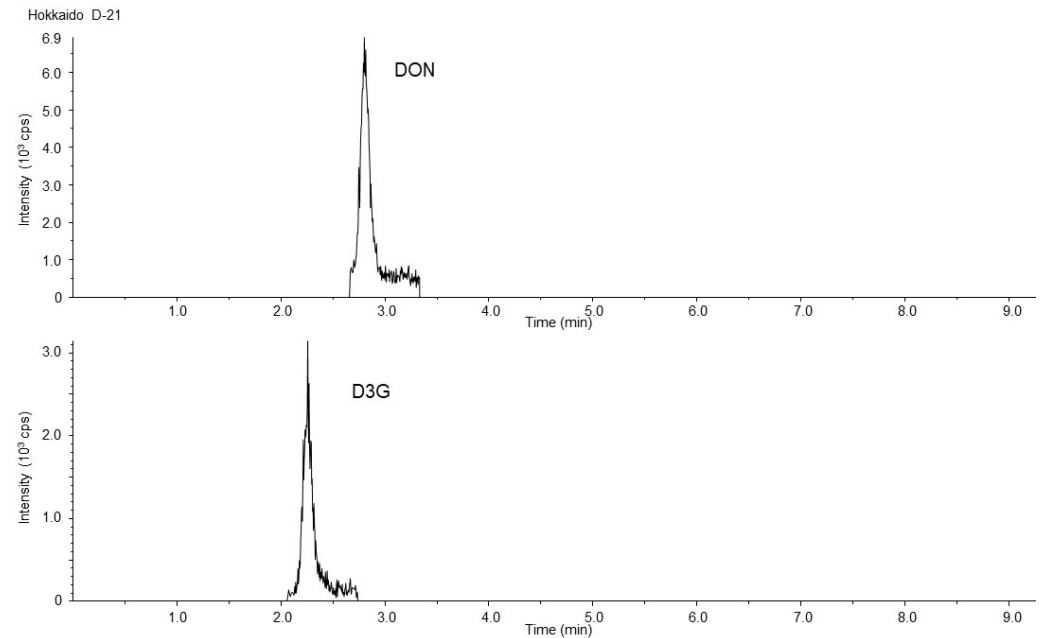

(c)
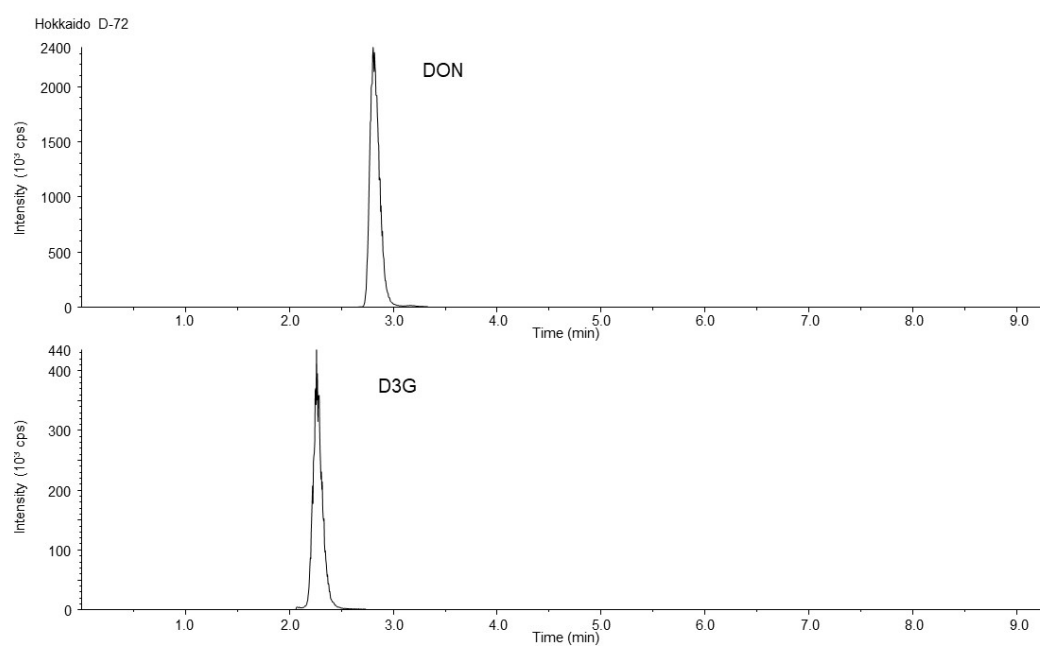

Fig. 2 Typical LC-MS/MS chromatograms of a commercial standard compared to DON and D3G of 'Variety $A$ ' in each experimental plot fortified with VEL.

(a: $100 \mu \mathrm{g} / \mathrm{kg}$ standard DON, b: 'Variety A' with silk insertion, c: 'Variety A' with kernel injection). 
Symptoms of Gibberella ear rot were observed in most of the harvested ears (Fig. 3). The concentration of DON in the dried ears ranged from 0.02 to $36.8 \mathrm{mg} / \mathrm{kg}$ for those treated with silk insertion procedure (Table 2). Whereas the DON levels ranged from 13.3 to $53.3 \mathrm{mg} /$ $\mathrm{kg}$ for those with kernel injections (Table 3), which were considered to be high levels of contamination. Significant differences were observed among all varieties with regards to both DON and D3G content (Tukey's HSD test; $P<0.05$ ). D3G/DON ratio ranged from 12.3 to 50.5 $\%$ for silk insertion, and 6.2 to $19.5 \%$ for kernel injection, respectively. Significant correlation between DON and D3G content was observed, with the coefficient of determination of 0.90 for silk insertion, and 0.54 for kernel injection (Fig. 4).

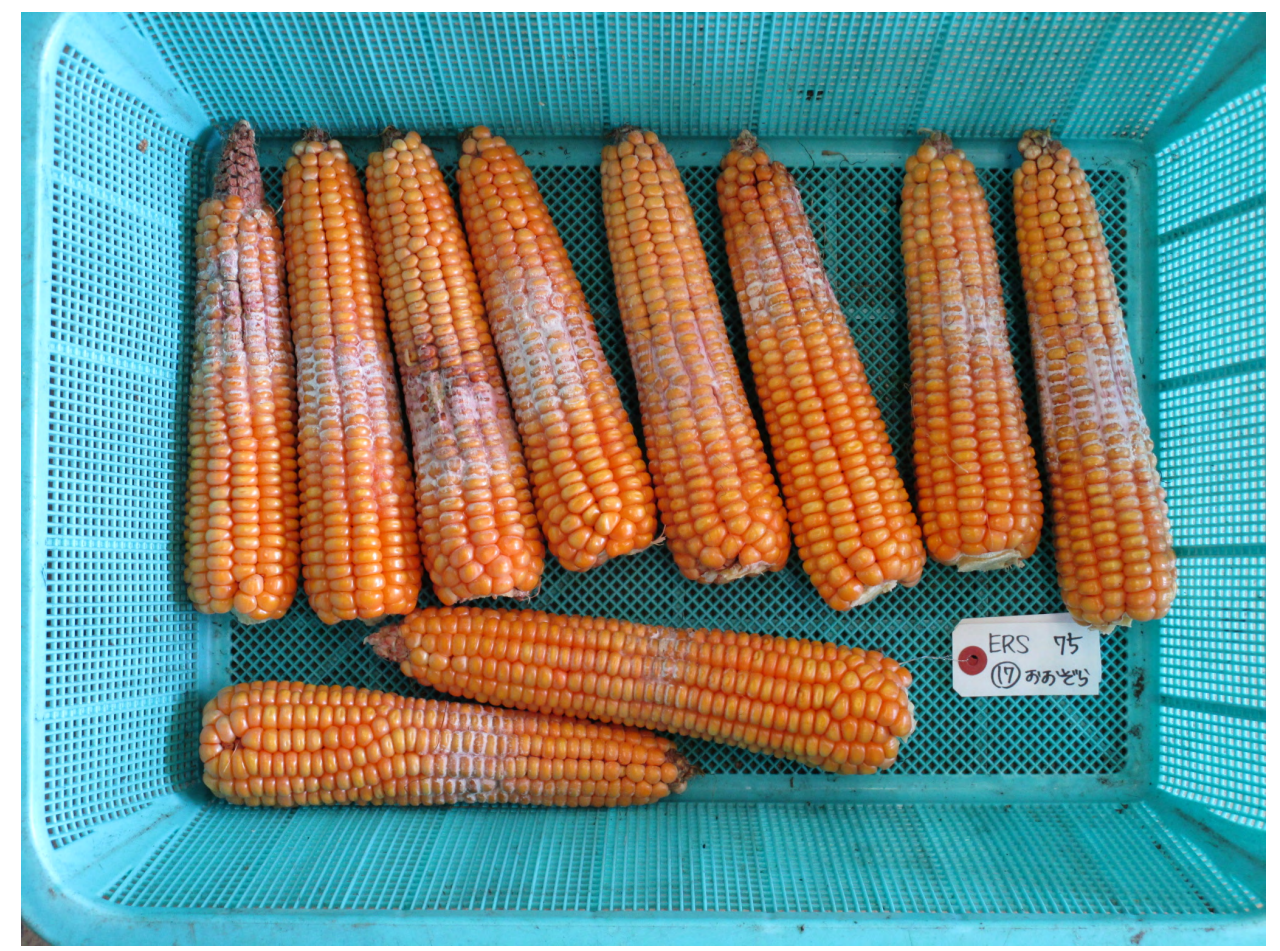

Fig. 3 Symptoms of Gibberella ear rot in susceptible control variety 'Ohzora' with kernel injection.

Table 2 DON and D3G concentration in dried ears subjected to silk insertion method

\begin{tabular}{lccc}
\hline & $\begin{array}{c}\text { DON } \\
(\mathrm{mg} / \mathrm{kg})\end{array}$ & $\begin{array}{c}\text { D3G } \\
(\mathrm{mg} / \mathrm{kg})\end{array}$ & $\begin{array}{c}\text { D3G / DON } \\
\text { ratio (\%)* }\end{array}$ \\
\hline Daichi + & $24.5^{\mathrm{ab}}$ & $4.40^{\mathrm{ab}}$ & 12.3 \\
Ohzora + & $29.1^{\mathrm{ab}}$ & $6.84^{\mathrm{ab}}$ & 16.1 \\
Kimimaru $^{+}$ & $0.02^{\mathrm{b}}$ & $0.01^{\mathrm{b}}$ & 22.0 \\
Variety A (RM 106) ₹ & $0.10^{\mathrm{b}}$ & $0.07^{\mathrm{b}}$ & 50.5 \\
Variety B (RM 110) $\neq$ & $36.8^{\mathrm{a}}$ & $7.53^{\mathrm{a}}$ & 14.1 \\
34N84 § & $0.25^{\mathrm{b}}$ & $0.09^{\mathrm{b}}$ & 26.0 \\
\hline
\end{tabular}

Different letters in the same column indicate significant difference (Tukey's HSD test; $P<0.05$ ).

* $(\mathrm{D} 3 \mathrm{G} / 517.1) /(\mathrm{DON} / 355.1) \times 100$

$+F_{1}$ varieties bred at HARC

₹ Commercial varieties

$\S$ Old varieties
Table 3 DON and D3G concentration in dried ear subjected to kernel injection method

\begin{tabular}{|c|c|c|c|}
\hline & $\begin{array}{c}\text { DON } \\
(\mathrm{mg} / \mathrm{kg})\end{array}$ & $\begin{array}{c}\text { D3G } \\
(\mathrm{mg} / \mathrm{kg})\end{array}$ & $\begin{array}{c}\text { D3G / DON } \\
\text { ratio (\%) }\end{array}$ \\
\hline Daichi ${ }^{+}$ & $45.2^{\mathrm{abc}}$ & $10.4^{\mathrm{ab}}$ & 15.8 \\
\hline Tsukikou No.682 † & $19.6^{\mathrm{de}}$ & $3.17^{c}$ & 11.1 \\
\hline Tsukikou No.683 † & $53.3^{\mathrm{a}}$ & $6.75^{\mathrm{ac}}$ & 8.70 \\
\hline Tsukikou No.684 † & $28.8^{\mathrm{abe}}$ & $5.64^{\mathrm{ac}}$ & 13.5 \\
\hline Tsukikou No.685 † & $20.0^{\text {cde }}$ & $1.82^{\mathrm{c}}$ & 6.24 \\
\hline Tsukikou No.686 † & $46.8^{\mathrm{ab}}$ & $9.63^{a b}$ & 14.1 \\
\hline Papirika † & $37.0^{\text {abe }}$ & $6.20^{\mathrm{ac}}$ & 11.5 \\
\hline Tachipirika † & $13.3^{\mathrm{e}}$ & $2.68^{\mathrm{c}}$ & 13.8 \\
\hline Ohzora ${ }^{+}$ & $39.5^{\mathrm{abd}}$ & $11.2^{\mathrm{a}}$ & 19.5 \\
\hline Variety A (RM 106) ₹ & $22.3^{\text {be }}$ & $4.74^{b c}$ & 14.6 \\
\hline Tiberius § & $37.3^{\text {abe }}$ & $5.06^{\mathrm{bc}}$ & 9.31 \\
\hline Dukas § & $29.2^{\mathrm{abe}}$ & $5.58^{\mathrm{ac}}$ & 13.1 \\
\hline
\end{tabular}

Different letters in the same column indicate significant difference (Tukey's HSD test; $P<0.05$ ).

* $(\mathrm{D} 3 \mathrm{G} / 517.1) /(\mathrm{DON} / 355.1) \times 100$

$+F_{1}$ varieties bred at HARC

₹ Commercial varieties

$\S$ Old varieties 


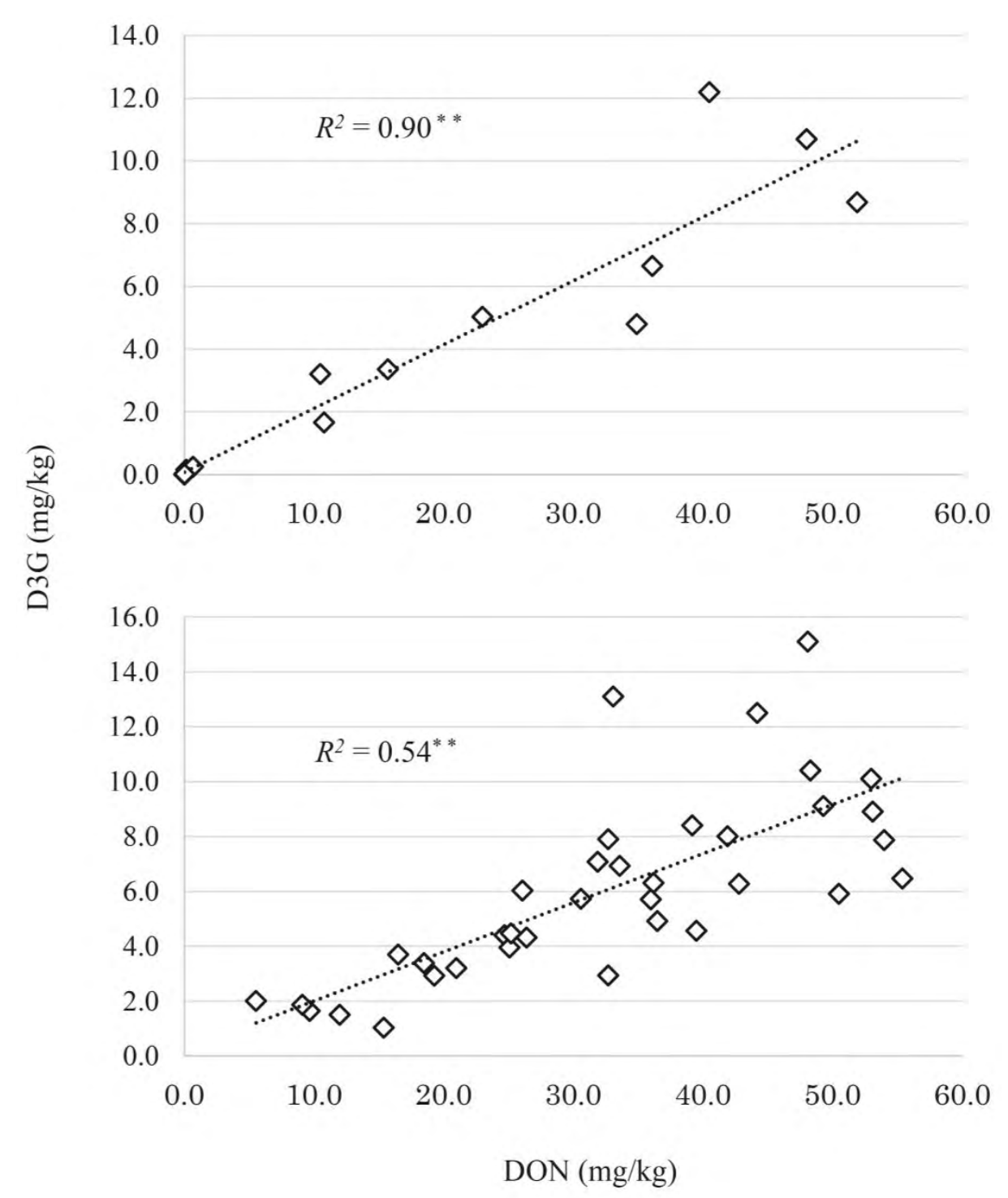

Fig. 4 Correlation of DON and D3G content in dried ears.

(above: silk insertion, $\mathrm{N}=18$; below: kernel injection, $\mathrm{N}=36, * *: P<0.01$ ).

In this study, high levels of DON content was observed in both, plants treated using silk insertion and kernel injection plots. The optimal temperature for the DON-producing F. graminearum is lower (cooler) than that required for other mycotoxin; fumonisin, and humid conditions favor advancing from silking to the milk ripe stages ${ }^{16), 17)}$. From early August to early September in 2015, the conditions in the fields were favorable for the growth of $F$. graminearum and DON production $(180 \mathrm{~mm}$ total rain fall, and an average temperature of $21.3^{\circ} \mathrm{C}$ ). In addition, our study involved artificial inoculations of $F$. graminearum, such as the silk insertion and kernel injection. Therefore, these circumstances can be much more severe for the plants than a naturally-occurring infection. Our findings may reflect these attributes.

Commercial 'Variety A' displayed high resistance in the silk insertion treatments, while less resistance in kernel injection. Also, varieties 'Kimimaru' and '34N84' were resistant in the silk insertion method, although they were not tested using the kernel injection. 'Kimimaru' was bred at HARC as a resistant variety for Fusarium ear rot and fumonisin contamination, therefore, it also seemed to be the preferred in terms of DON content compared to the general varieties tested. Previous studies have highlighted that the resistance for mycotoxin contamination differs between the silk insertion and kernel injection methods, that the susceptibility tends to vary on an annual basis, and on the environmental conditions ${ }^{17), 18)}$. For example, 'Variety A' seemed to have "insertion resistance" in the lines subjected to silk insertion but might not display "extension resistance" in the lines subject to kernel injection ${ }^{18)}$. It should be noted that DON-resistant maize varieties 
display stable resistance over time regardless of the attributes (silk, kernel, natural infection, etc.). Multiyear experimental trials will be required to identify maize varieties that are consistently DON-resistant.

D3G content was lower than that of DON in all the field experiments. Although there have been a few cases of occasionally higher levels of D3G (beer barley sample in the Czech Republic) ${ }^{19}$, , our results are in agreement with those of several reports ${ }^{20), 21), 22)}$. The D3G/DON ratio ranged from 6.2 to $50.5 \%$. The varieties with the highest ratio had low DON values especially in silk insertion plot, whereas the ones with the lowest ratio were those with kernel injection and hence, the low D3G value. The ratio is often suggested as an indicator of DON detoxification activity ${ }^{20)}$. In this study, DON content for 'Variety A', 'Kimimaru' and '34N84' in silk insertion were low, and the ratio were over $20 \%$. These varieties should be further evaluated as potential candidates for stable DON resistance.

The coefficient of determination for DON and D3G were significant in both the experimental plots $\left(R^{2}=\right.$ 0.90 and 0.54 ), and the findings were similar to a previous study ${ }^{22)}$. Although toxicity of D3G is less than that of DON, some reports suggest the risk that it could be reversed to DON via hydrolysis in animals or humans ${ }^{23), 24), 25)}$. In addition, most of the varieties examined in this study accumulated D3G at non-negligible levels. Therefore, one should be aware that DON concentration measured using ELISA may occasionally overestimate the actual amounts of DON, particularly because the values obtained may represent DON and D3G ${ }^{26)}$.

Previous study indicated high correlation between DON content and Gibberella ear rot symptoms (ratings) in silk insertion ${ }^{27)}$. Since the symptoms have the potential as an indicator for screening DON-resistant maize varieties, further examination will be required, considering that DON and D3G were highly correlated in our results.

Our study is the first to report DON and D3G content in several forage corn varieties treated using different inoculation methods (silk and kernel). Since the data shown here were obtained from a single-year trial, further studies are required to apply these findings in future breeding programs to ensure safe and stable forage supply.

\section{Acknowledgements}

This research was supported in part by the Advanced Analysis Center Research Supporting Program of National Agriculture and Food Research Organization (NARO). We also thank Ms. H. Akitomi for her technical assistance in sample preparation and Ms. K. Minato for providing her photographs of this manuscript.

\section{References}

1) Trenholm, H.L., Hamilton, R.M., Friend, D.W., Thompson, B.K., Hartin, K.E.: Feeding trials with vomitoxin (deoxynivalenol)-contaminated wheat: effects on swine, poultry, and dairy cattle. J Amer Vet Med Assn ens, 185, 527-531 (1984)

2) Diekman, M.A., Green, M.L.: Mycotoxins and reproduction in domestic livestock. J Anim Sci, 70, 1615-1627 (1992)

3) Hiraoka, H.: Occurrence and Control for Fusarium Mycotoxins in Forage Maize. Jpn Journal of Grass Sci, 61, 107114 (2015) (in Japanese)

4) Ilgen, P., Hadeler, B., Maier, F.J., Schäfer, W.: Developing kernel and rachis node induce the trichothecene pathway of Fusarium graminearum during wheat head infection. Mol Plant Microbe Interact, 22, 899-908 (2009)

5) Boenisch, M.J., Schäfer, W.: Fusarium graminearum forms mycotoxin producing infection structures on wheat. BMC Plant Biol, 11, 110 (2011)

6) Karlovsky, P.: Biological detoxification of the mycotoxin deoxynivalenol and its use in genetically engineered crops and feed additives. Appl Microbiol Biotechnol, 91, 491-504 (2011)

7) Shin, S., Torres-Acosta, J.A., Heinen, S.J., McCormick, S., Lemmens, M., Paris, M.P., Berthiller, F., Adam, G., Muehlbauer, G.J.: Transgenic Arabidopsis thaliana expressing a barley UDP-glucosyltransferase exhibit resistance to the mycotoxin deoxynivalenol. J Exp Bot, 63, 4731-4740 (2012)

8) Rychlik, M., Humpf, H.U., Marko, D., Dänicke, S., Mally, A., Berthiller, F., Klaffke, H., Lorenz, N.: Proposal of a comprehensive definition of modified and other forms of mycotoxins including "masked" mycotoxins. Mycotoxin Res, 30, 197-205 (2014)

9) Kanatani, R., Takeda, K.: A Method for Mass Sporulation in a Scab Disease Pathogen (Fusarium graminearum Schwabe). Nogaku Kenkyu, 62, 177-189 (1991) (in Japanese)

10) Reid, L.M., Woldemariam, T., Zhu, X., Stewart, D.W., Schaafsma, A.W.: Effect of inoculation time and point of entry on disease severity in Fusarium graminearum, Fusarium verticillioides, or Fusarium subglutinans inoculated maize ears. Can J Plant Pathol, 24, 162-167 (2002)

11) Clements, M.J., Kleinschmidt, C.E.: Evaluation of Inoculation Techniques for Fusarium Ear Rot and Fumonisin Contamination of Corn. Plant Dis, 87, 147-153 (2003)

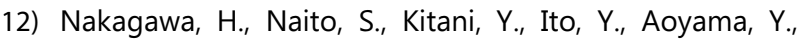
Koyama, M., Hiejima, Y., Nakamura, K., Miyazaki, H., Morita, H-I., Tamura, M., Mochizuki, N., Nakamura, M., Seki, Y., Kadokura, H., Ikeda, H., Horie-Ishiguro, T., Saito, Y., Tajima, M., Shigematsu, Y., Kasama, K., Oguma, Y., Sogo, Y., Goto, T., Hirayae, K.: Harmonized Collaborative Validation of a Simultaneous and Multiple Determination Method for Nivalenol, Deoxynivalenol, T-2 Toxin, HT-2 Toxin, and Zearalenone in Wheat and Barley by Liquid Chromatography Coupled to Tandem Mass Spectrometry (LC-MS/MS). J Anal Bioanal Tech, Special Issue S6 (2014) http://dx.doi.org/10.4172/2155-9872.S6-002

13) Kawanishi, M., Kitani, Y., Suenaga, K., Shinoda, T.: Single laboratory validation of a determination method for Fusarium toxins including deoxynivalenol-3-glucoside in wheat and barley. Procceding of the 81th meeting of the Japanese Society of Mycotoxicology, pp.31 (2018) (in Japanese)

14) R Core Team: R: A language and environment for statistical computing. (2016) R Foundation for Statistical Computing, Vienna, Austria https://www.R-project.org/ 
15) Hothorn, T., Bretz, F., Westfall, P.: Simultaneous Inference in General Parametric Models. Biometrical Journal, 50, 346-363 (2008)

16) Bernhoft, A., Torp, M., Clasen, P.E., Løes, A.K., Kristoffersen, A.B.: Influence of agronomic and climatic factors on Fusarium infestation and mycotoxin contamination of cereals in Norway. Food Addit Contam Part A Chem Anal Control Expo Risk Assess, 29, 1129-1140 (2012)

17) Minato, K.: Contamination of Gibberella ear rot and Deoxynivalenol in forage corn. J Jpn Vet Med Assoc, 56, 609-614 (2012) (in Japanese)

18) Okabe, I.: Is artificial inoculation or natural infection better for evaluating forage maize cultivars for resistance to fumonisin contamination? Jpn J Phytopathol, 83, 151-157 (2017) (in Japanese)

19) Lancova, K., Hajslova, J., Poustka, J., Krplova, A., Zachariasova, M., Dostalek, P., Sachambula, L.: Transfer of Fusarium mycotoxins and 'masked' deoxynivalenol (deoxynivalenol-3-glucoside) from field barley through malt to beer. Food Addit Contam Part A Chem Anal Control Expo Risk Assess, 25, 732-744 (2008)

20) Berthiller, F., Crews, C., Dall'Asta, C., Saeger, S.D., Haesaert, G., Karlovsky, P., Oswald, I.P., Seefelder, W., Speijers, G., Stroka, J.: Masked mycotoxins: a review. Mol Nutr Food Res, 57, 165-186 (2013)

21) Lemmens, M., Steiner, B., Sulyok, M., Nicholson, P., Mesterhazy, A., Buerstmayr, H.: Masked mycotoxins: Does breeding for enhanced Fusarium head blight resistance result in more deoxynivalenol-3-glucoside in new wheat varieties? World Mycotoxin J, 9, 741-754 (2016)

22) Nakagawa, H., He, X., Matsuo, Y., Singh, P.K., Kushiro, M.: Analysis of the Masked Metabolite of Deoxynivalenol and Fusarium Resistance in CIMMYT Wheat Germplasm. Toxins, 9, 238 (2017)

23) Nagl, V., Schwartz, H., Krska, R., Moll, W.D., Knasmüller, S., Ritzmann, M., Adam, G., Berthiller, F.: Metabolism of the masked mycotoxin deoxynivalenol-3-glucoside in rats. Toxicol Lett, 213, 367-373 (2012)

24) Dall'Erta, A., Cirlini, M., Dall'Asta, M., Del Rio, D., Galaverna, G., Dall'Asta, C.: Masked mycotoxins are efficiently hydrolyzed by human colonic microbiota releasing their aglycones. Chem Res Toxicol, 26, 305-312 (2013)

25) Gratz, S.W., Duncan, G., Richardson, A.J.: The human fecal microbiota metabolizes deoxynivalenol and deoxynivalenol-3-glucoside and may be responsible for urinary deepoxy-deoxynivalenol. Appl Environ Microbiol, 79, 1821-1825 (2013)

26) Ruprich, J., Ostrý, V.: Immunochemical methods in health risk assessment: cross reactivity of antibodies against mycotoxin deoxynivalenol with deoxynivalenol-3-glucoside. Cent Eur J Public Health, 16, 34-37 (2008)

27) Reid, L.M., Sinha, R.C.: Maize maturity and the development of Gibberella ear rot symptoms and deoxynivalenol after inoculation. Eur J Plant Pathol, 104, 147-154 (1998) 